\title{
Forced Vibration Analysis of Milling Machine's Hexapod Table under Machining Forces
}

\author{
Siamak Pedrammehr1,2,* - Mehran Mahboubkhah ${ }^{1}$ - Mohammad Reza Chalak Qazani ${ }^{3}$ - \\ Arash Rahmani4 - Sajjad Pakzad4 \\ ${ }^{1}$ University of Tabriz, Faculty of Mechanical Engineering, Iran \\ 2 Sabanci University, Faculty of Engineering and Natural Sciences, Turkey \\ ${ }^{3}$ Tarbiat Modares University, Department of Mechanical Engineering, Iran \\ 4 Islamic Azad University-Ajabshir Branch, Faculty of Mechanical Engineering, Iran
}

Assuming a sinusoidal machining force, the forced vibration of a machine tools' hexapod table in different directions is addressed in the present study. A vibration model for the hexapod table is developed and the relevant explicit equations are derived. In the vibration equation of the table, the pods are assumed as spring-damper systems and the equivalent stiffness and damping of the pods are evaluated using experimental results obtained by modal testing on one pod of the hexapod table. The results of the analytical approach have been verified by FEM simulation. The theoretical and FEM results exhibit similar trends in changes and are close to each other. The vibration of the table in different positions has been studied for rough and finish machining forces for both down and up milling. The ranges of resonance frequencies and vibration amplitudes have also been investigated. The safe functional modes of the table in terms of its upper platform's position have subsequently been determined.

Keywords: hexapod, machine tool, vibration, modal analysis, cutting force

\section{INTRODUCTION}

In recent years, the parallel mechanism has found extensive applications as the table or spindle of machine tools. Stiffness and appropriate vibration behavior are among the primary requirements for precision machining. This requires a thorough understanding of the dynamics of the mechanism. The purpose of the present study is to partially meet this need and fill the gap existing in the literature in this respect.

The control of vibration in the machine tools with the aim of improving their performance has been the focus of much research in the literature. Dohner et al. [1] have proposed a finite element method (FEM) model to analyse chatter in the spindle of a milling machine set on a hexapod platform. In their model, in order to effectively control the chatter, flexible parts were added to the borders of the spindle. However, the analytical vibration relations of the hexapod was not given. Thus, their results could not be generalized to hexapods used as a machine table. Studies to examine vibrations of hexapods with applications in vibration isolation have been carried out. Hardage and Wiens [2] presented the results of a review of a mini-modal in a Hexel Tornado 2000, where they discussed flexibility modeling using finite elements. Their investigation suggested that characteristics of resonant frequency and stiffness are dependent on the configuration of the machine. Hardage [3] has studied the structural dynamics of parallel kinematic machine tools (PKMs). In another work, Wiens and Hardage [4] have developed a methodology to identify the parameters of the structural dynamics of PKMs. They derived the analytical model for the simulation of the vibration response and modal parameters for a PKM. The accuracy of the model was verified through experimental modal analysis. Ting et al. [5] have derived a dynamic model for a Stewart platformtype computer numerical control (CNC) machine by means of the Euler-Lagrange approach. The average type force model for the end milling process has also been included in the dynamic model. In their research, an appropriate estimator gain was designed for the parameter adaptation law, which is useful for the estimation of the cutting parameters. Mukherjee et al. [6] have studied the analysis of dynamics and vibration of a flexible Stewart platform. In their research, the dynamic equations were derived through the Newton-Euler approach and a dynamic stability index was developed and validated. Hong et al. [7] derived the vibration model of a parallel machine tool. In their model, the pods of the parallel mechanism were considered as spring-damper systems. They performed stability analysis through a combination of the regenerative cutting dynamics model and the vibration model. Mahboubkhah et al. [8] and [9] investigated the free vibrations and the range of natural frequencies of the machine tool's hexapod table using different configurations and two different analytical methods. According to their work, in the first method, the mass of the pods is ignored and, in 
the second one, the mass of the pods is taken into account in the calculation of the natural frequencies of the platform. Pedrammehr et al. [10] have investigated free vibrations, natural frequencies and mode shapes of the hexapod table using different configurations and two different analytical methods. They also investigated the factors influencing the dynamic features of the hexapod table.

In the present study, the time variable sinusoid force with specified frequency and amplitude has been assumed to be the external force acting on the platform and the forced vibration of the moving platform has been examined analytically. The resonance frequencies and range of vibrations of the platform have been calculated. To validate the analytical method, the forced vibration of the platform is examined by FEM simulation using the harmonic analysis in ANSYS Workbench. Resonance frequencies and the vibrations of the platform in different directions have been obtained for different configurations of the mechanism. Theoretical and FEM results are close to each other, exhibiting similar trends in changes. To closely investigate the forced vibration as the result of machining on the hexapod table, milling forces are modeled analytically and forced vibrations of the platform have been studied under different conditions of roughing and finishing in both up milling and down milling operations. After calculating the resonance frequencies and the range vibrations of the platform, proper configurations of the platform are presented in order to avoid dynamic instability in different machining operations.

\section{VIBRATION MODEL OF THE HEXAPOD TABLE}

A schematic view of the hexapod table is shown in Fig. 1. The table is installed on the workshop floor into a rigid foundation.

The hexapod under investigation consists of a moving platform, a stationary platform, and six similar pods with changing lengths connecting the two aforementioned platforms to each other. The pods are connected to the upper moving platform through spherical joints and to the lower stationary platform through universal joints.

The hexapod table under study was developed for a three-axis CNC milling machine. The physical specifications of the hexapod are presented in Appendix 1.

The vibration model proposed by the authors for the table is illustrated in Fig. 2.

To describe the motion of the upper platform as the end effecter, two coordinate systems have been used. The moving platform frame $\{\mathbf{P}\}$ is attached to the geometrical center of the moving platform. The location and orientation of the moving platform frame $\{\mathbf{P}\}$, is specified according to the base frame $\{\mathbf{W}\}$, which is attached to the geometrical center of the stationary platform.

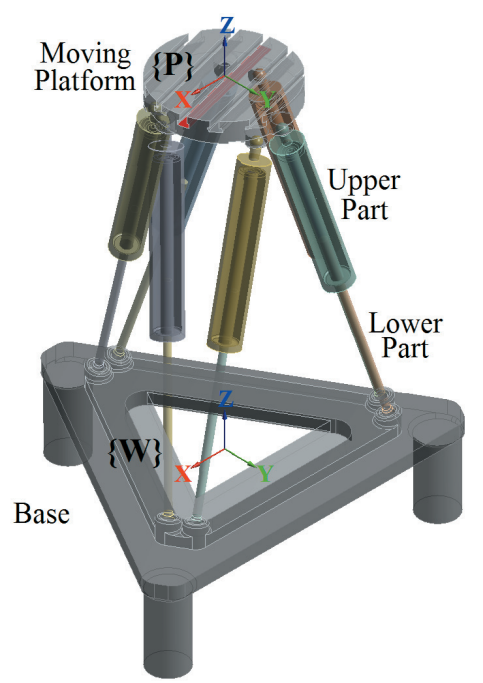

Fig. 1. Schematic view of the milling machines' hexapod table

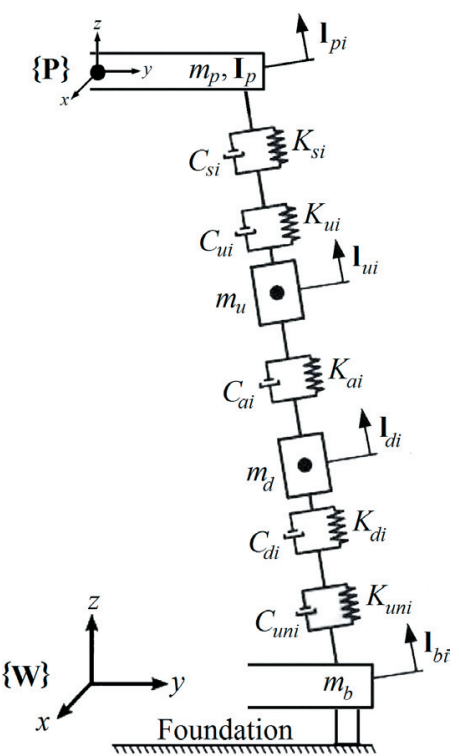

Fig. 2. Vibration model of the hexapod table

In the vibration model of the table, pods and joints are taken to be flexible. Joints are frictionless and with negligible rotational damping. It is assumed that the moving platform is rigid in order to withstand deflection under the payload.

The flexible model of the manipulator is shown in Fig. 2 (only one pod is depicted). The parameters 
shown in this figure are as follows: $m_{p}, m_{u}, m_{d}$ and $m_{b}$ are, respectively, the total mass of the moving platform (including payload), the mass of upper part of pods, the mass of lower part of pods and the mass of the base platform. $\mathbf{I}_{p}$ is the inertia tensor of the moving platform and the payload in the base frame. $\mathbf{l}_{p i}, \mathbf{l}_{u i}, \mathbf{l}_{d i}$ and $\mathbf{l}_{b i}$ are the displacements of the moving platform, upper and lower parts of the pods, and base along $i^{\text {th }}$ pod's extensional axis $(i=1$ to 6 for six pods), respectively. $C_{s i}, C_{u i}, C_{a i}, C_{d i}$ and $C_{u n i}$ are, respectively, the damping coefficients of the spherical joints, the upper part of pods, the sliding joints, the lower part of pods, and the universal joints. $K_{s i}, K_{u i}, K_{a i}, K_{d i}$ and $K_{u n i}$ are also the stiffness coefficients of the spherical joints, the upper part of pods, the sliding joints, the lower part of pods, and the universal joints, respectively. The total damping and stiffness coefficient of the upper joints of the platform, $C_{T i}$ and $K_{T i}$, can also be theoretically obtained by a series combination of damper's and spring's rules [8], respectively. Details for $\mathbf{I}_{p}$ and theoretical $C_{T i}$ and $K_{T i}$ are given in the Appendix 2.

\section{EQUIVALENT STIFFNESS AND DAMPING COEFFICIENTS OF THE TABLE}

In the given model, the pod is linked in the bottom to the fixed platform, moves with the moving platform in the upper part and bears part of the mass of the platform, where the elastic elements are fixed at one end and at the other end bear the vibrational forces. So, modal testing by assuming the pod as a one-end post is close to the real situation; this is carried out by linking the pod form at the bottom to the base and agitating the pod from the upper part (Fig. 3).

According to Fig. 3, the modal test for one pod of the hexapod table is carried out for three situations: fully limited, semi-open and fully open. To do the experiment, a pod of the hexapod table, a piezoelectric accelerometer (type 4507, B\&K Inc.) and a shaker (type 4809, B\&K Inc.) are used.

Considering the special boundary condition of the mechanism with fixed degrees of freedom (DOFs) in earth connection of the structure, the pod is fixed at the bottom and the shaker is adjusted and suspended from the upper part in the ball screw direction and linked through a push rod to the upper part of the platform. A force sensor is located in the upper part of the pod in series with the alternate forces exerted by oscillator. An accelerometer is also linked to the upper part of the pod in the direction of its axis.

The force is exerted in a periodic random manner on the pod to agitate all vibration modes. The experiments are conducted to find the natural frequencies of length and stiffness of the pods. Thus, accelerometers are always located in the direction of longitudinal agitation of the pods and as a result, longitudinal accelerations and forces are measured.
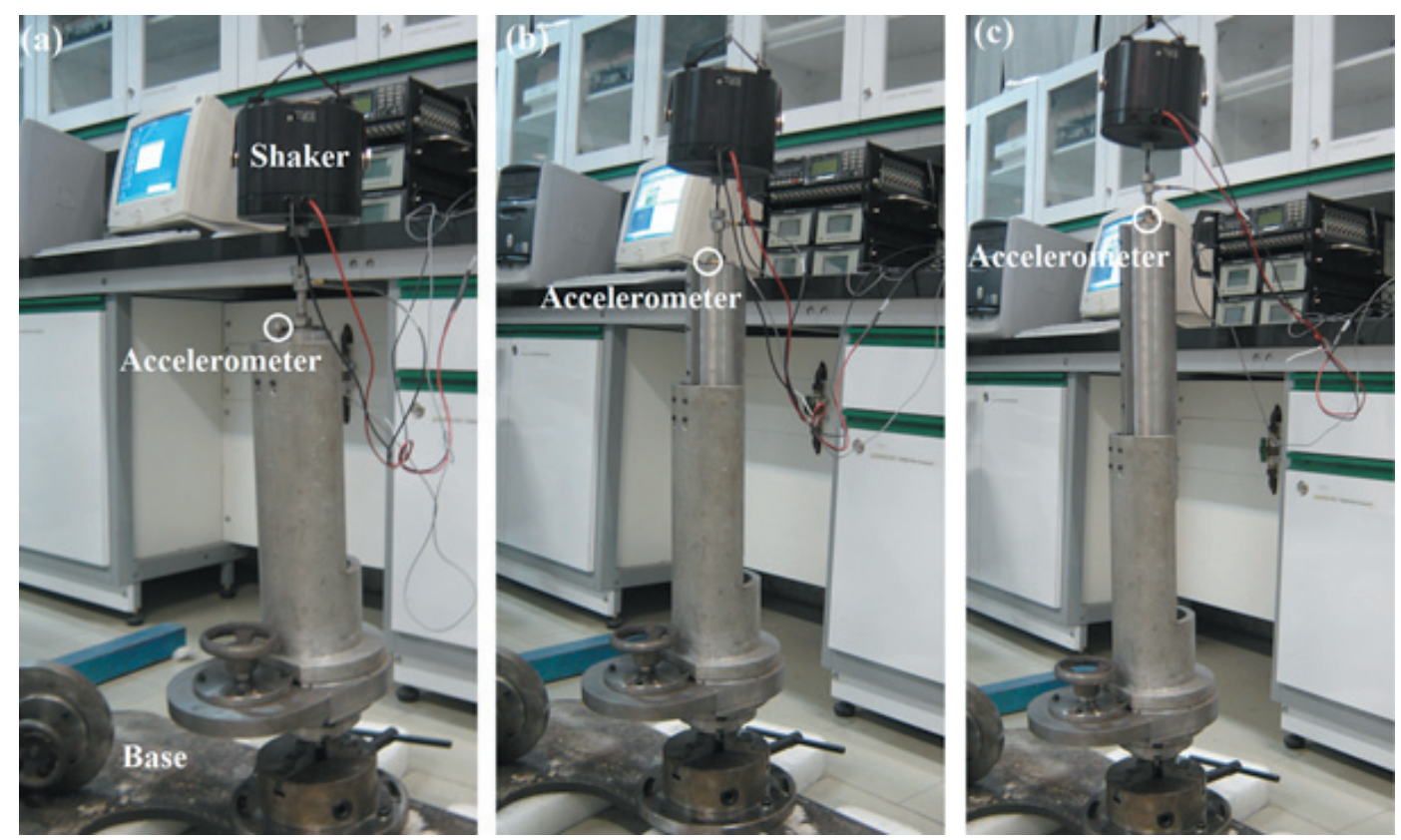

Fig. 3. Modal analysis of the pod in a one-end-engaged situation: a) pod in the fully limited situation, b) pod in the semi-open situation, c) pod in a fully open situation 
Force exertion is carried out alternately, in the range lower than $1 \mathrm{~N}$, and at a starting frequency from 0 to $6.4 \mathrm{kHz}$ on the pods. These forces are adjusted such that the accelerometer can measure the responses. If the force exerted is rather high, the sensor will be agitated and moved so that it will not measure correctly. Thus, the abovementioned force should be adjusted to an optimum level.

The signal of the accelerometer and the shaker force are collected and analysed using a pulse system (type 3560, B\&K Inc.). Using the Fast Fourier Transform (FFT) algorithm, the frequency response functions (FRFs) of the mechanism were extracted. Using STAR software, the results were analysed for different situations of the pod. The force and acceleration curves as frequency are given for each measurement and their ratio are used to calculate the stiffness. The results of the modal test are shown in the Fig. 4 as acceleration and dynamic stiffness curves of the pods for all situations under study. Curve fitting is utilized to calculate modal parameters such as frequency, damping and mode shape [11]. In this paper, the local single degree of freedom (SDOF) category of curve fit is employed to obtain the modal parameters of pods.
Once the FRF curves are obtained, damping ratio and natural frequency can be calculated easily using star software.

As the largest value of the force is located at the resonance point, static stiffness, $K_{S t}$, can be calculated from the function below [12]:

$$
K_{S t}=F_{D y n} / 2 X_{D y n} \zeta,
$$

where $F_{D y n}$ denotes the exerted force, $X_{D y n}$ the displacement of the element in the direction of the force in dynamic situation and $\zeta$ denotes the damping ratio.

Table 1. Acceleration and dynamic stiffness for all situations in modal test

\begin{tabular}{lcccc}
\hline $\begin{array}{l}\text { Situation } \\
\text { of pod }\end{array}$ & $\begin{array}{c}\text { Natural freq. } \\
{[\mathrm{Hz}]}\end{array}$ & $\begin{array}{c}\text { Damping } \\
\text { ratio } \zeta\end{array}$ & $\begin{array}{c}\text { Stiffness } K_{T i} \\
{[\mathrm{~N} / \mathrm{m}]}\end{array}$ & $\begin{array}{c}\text { Damping } C_{T i} \\
{[\mathrm{Ns} / \mathrm{m}]}\end{array}$ \\
\hline $\begin{array}{l}\text { Completely } \\
\text { closed pod }\end{array}$ & 2546 & 0.033 & $2.50 \mathrm{e} 8$ & 1031 \\
\hline $\begin{array}{l}\text { Semi-open } \\
\text { pod }\end{array}$ & 2466 & 0.037 & $1.46 \mathrm{e} 8$ & 726 \\
\hline $\begin{array}{l}\text { Completely } \\
\text { open pod }\end{array}$ & 2368 & 0.027 & $1.05 \mathrm{e} 8$ & 366 \\
\hline
\end{tabular}

$K_{D y n\left(\omega=\omega_{\circ}\right)}$ is defined at the resonance point as the following:

$$
K_{D y n\left(\omega=\omega_{\circ}\right)}=F_{D y n} / X_{D y n} .
$$

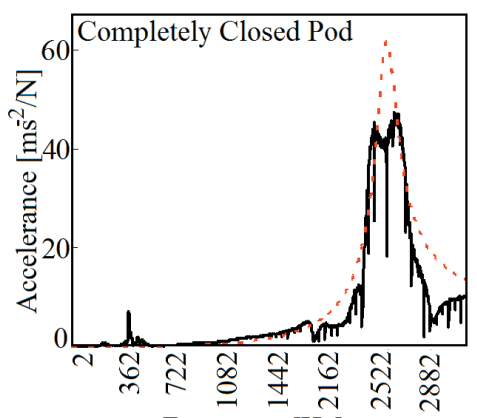

Frequency $[\mathrm{Hz}]$

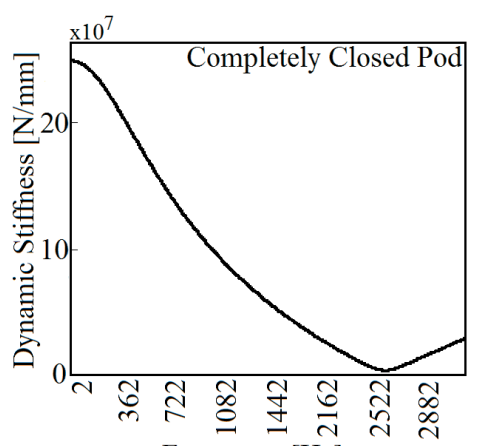

Frequency [Hz]
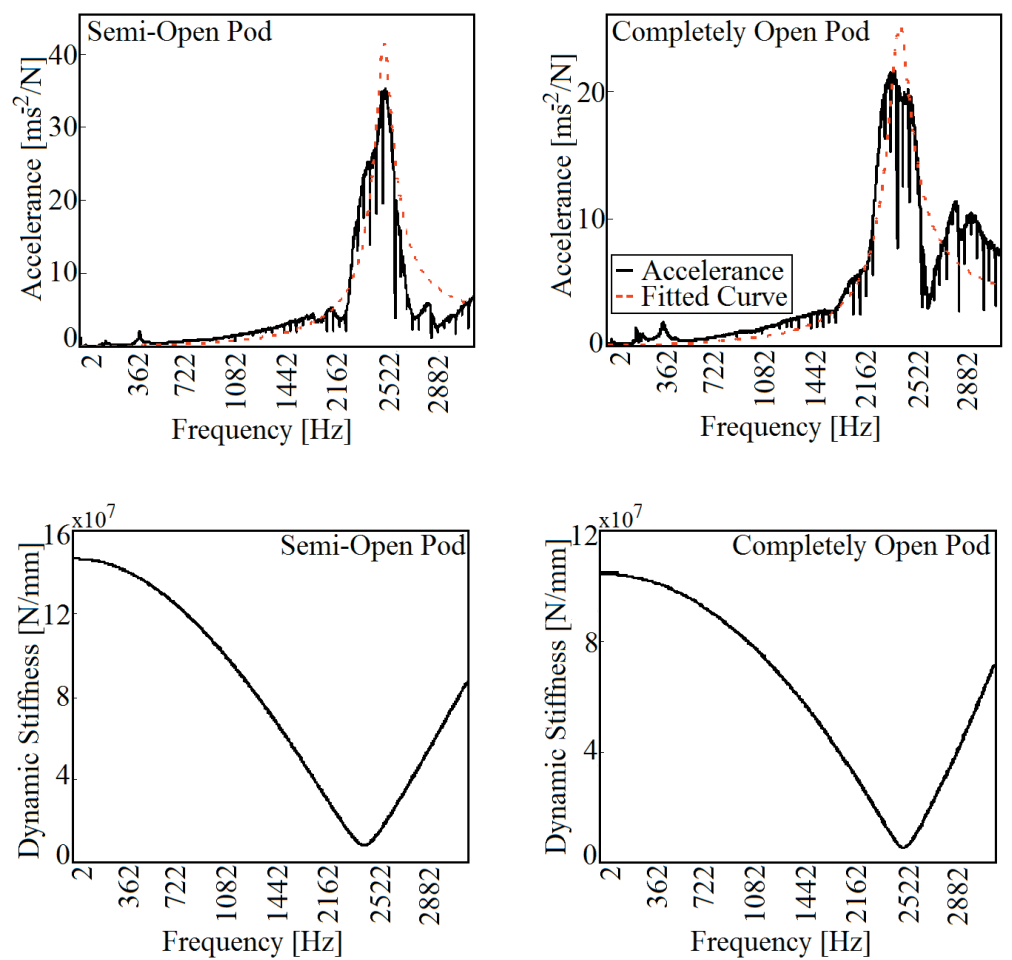

Fig. 4. Acceleration and dynamic stiffness for all situations in the modal test 
According to Eqs. (1) and (2), $K_{S t}$ is calculated as the following:

$$
K_{S t}=K_{D y n\left(\omega=\omega_{o}\right)} / 2 \zeta .
$$
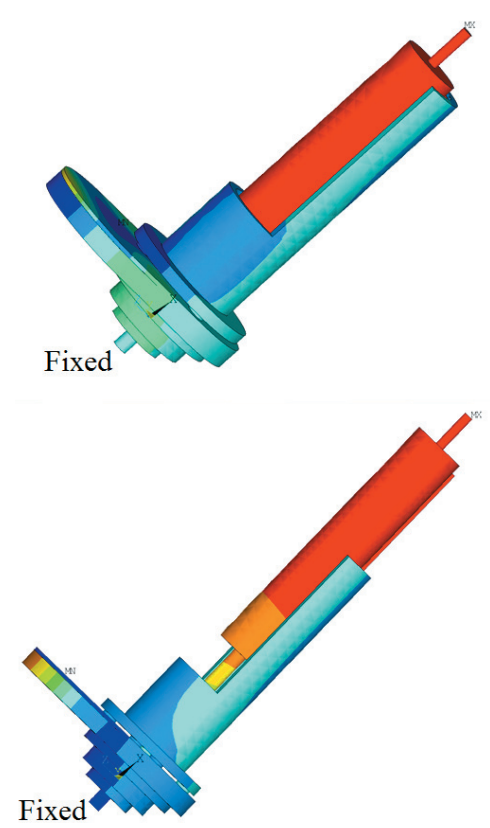

(a)

(b)

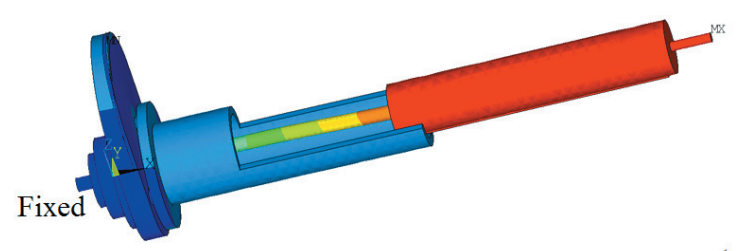

(c)

Fig. 5. Mode of vibration in a one-end-fixed situation; a) pod in a fully limited situation, b) pod in a semi-open situation, c) pod in a fully open situation

Modal parameters of one of the pods of the hexapod table, namely, natural frequency, dumping ratio and static stiffness are calculated from modal test results for all situations and are given in Table 1. In order to corroborate the results, a three dimensional model of the pod has been extracted in Solidworks, and the natural frequencies of the pod in three different conditions of completely closed, semi-open and completely open are also obtained using FEM modal analysis under ANSYS. It should be noted that the frequencies using FEM are noticeable by the mode shapes for each condition. Fig. 5 illustrates the mode shapes of vibration for a completely closed pod with a natural frequency of $2671 \mathrm{~Hz}$, a semi-open pod with natural frequency of $2516 \mathrm{~Hz}$ and a completely open pod with a natural frequency of $2453 \mathrm{~Hz}$. It is clear that the results for the experimental modal test are close to the results obtained by FEM.

\section{VIBRATION EQUATION OF THE TABLE}

Considering the equivalent stiffness and damping forces of the moving platform, the free-body diagram of the moving platform is illustrated in Fig. 6.

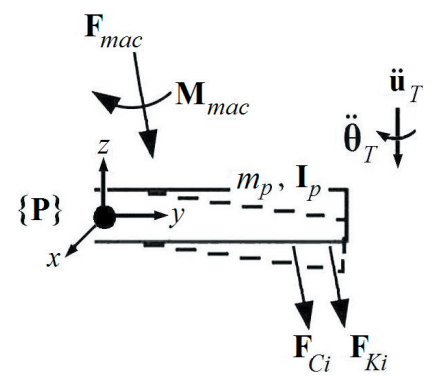

Fig. 6. Free-body diagram of the moving platform

In Fig. 6, $\ddot{\mathbf{u}}_{T}$ and $\ddot{\theta}_{T}$ are the linear and angular acceleration, respectively, of the platform expressed in frame $\{\mathbf{W}\} ; \mathbf{F}_{\text {mac }}$ and $\mathbf{M}_{\text {mac }}$, the harmonic machining force and moment vectors in local coordinate frame $\{\mathbf{P}\}$ being arbitrarily exerted to the moving platform, respectively. The force and moment can be expressed in $\{\mathbf{W}\}$ by the rotation transformation, $\mathbf{R}$. Details for $\mathbf{R}$ are given in Appendix 2. The gravity and coriolis forces are negligible in vibration analysis and have been ignored.

$\mathbf{F}_{C i}$ and $\mathbf{F}_{K i}$ are the total stiffness and damping forces, respectively, exerted on the platform and can be obtained as follows:

$$
\begin{gathered}
\mathbf{F}_{C i}=C_{T i} \Delta \mathbf{i}_{T i}, \\
\mathbf{F}_{K i}=K_{T i} \Delta \mathbf{l}_{T i},
\end{gathered}
$$

in which $\Delta \mathbf{i}_{T i}$ and $\Delta \mathbf{l}_{T i}$ are the absolute velocity and displacement of the junction along the $i^{\text {th }}$ pod's axis. Considering $\mathbf{J}^{-1}$ as an inverse Jacobian matrix (Appendix 2), $\Delta \dot{\mathbf{l}}_{T i}$ and $\Delta \mathbf{l}_{T i}$ can be expressed in terms of the linear velocity and displacement increments of the geometric center of the moving platform in the reference coordinate frame $\left(\dot{\mathbf{u}}_{T}, \dot{\theta}_{T}\right.$ and $\left.\mathbf{u}_{T}, \boldsymbol{\theta}_{T}\right)$, as follows:

$$
\begin{gathered}
\Delta \dot{\mathbf{I}}=\mathbf{J}^{-1}\left[\begin{array}{c}
\dot{\mathbf{u}}_{T} \\
\dot{\boldsymbol{\theta}}_{T}
\end{array}\right], \\
\Delta \mathbf{I}=\mathbf{J}^{-1}\left[\begin{array}{l}
\mathbf{u}_{T} \\
\boldsymbol{\theta}_{T}
\end{array}\right] .
\end{gathered}
$$


Considering the free body diagram of the moving platform illustrated in Fig. 6, the force equilibrium (Newton) equation and the moment equilibrium (Euler) equation for the geometric center of the moving platform can be written as follows:

$$
\begin{gathered}
m_{p} \ddot{\mathbf{u}}_{T}+\sum_{i=1}^{6} \mathbf{n}_{i} F_{C i}+\sum_{i=1}^{6} \mathbf{n}_{i} F_{K i}=-\mathbf{R} \mathbf{F}_{\text {mac }}, \\
\mathbf{I}_{p} \ddot{\boldsymbol{\theta}}_{T}+\sum_{i=1}^{6} \mathbf{q}_{i} \times \mathbf{n}_{i} F_{C i}+\sum_{i=1}^{6} \mathbf{q}_{i} \times \mathbf{n}_{i} F_{K i}= \\
=-\mathbf{R}\left(\mathbf{M}_{\text {mac }}+\mathbf{r} \times \mathbf{F}_{\text {mac }}\right) .
\end{gathered}
$$

where $\mathbf{n}_{i}$ and $\mathbf{q}_{i}$ are respectively the unit vector along the $i^{\text {th }}$ pod axis and the position vector of the $i^{\text {th }}$ platform connection point in frame $\{\mathbf{W}\} . \mathbf{r}$ is the position vector of the mass centre of the moving platform and payload in frame $\{\mathbf{W}\}$. Details for $\mathbf{r}$ are given in Appendix 2.

Substituting Eqs. (4) and (5) into Eqs. (8) and (9) and then coupling these equations yields:

$$
\begin{gathered}
{\left[\begin{array}{cc}
m_{p} \mathbf{I}_{3} & 0 \\
0 & \mathbf{I}_{p}
\end{array}\right]\left[\begin{array}{l}
\ddot{\mathbf{u}}_{T} \\
\ddot{\boldsymbol{\theta}}_{T}
\end{array}\right]+\mathbf{J}^{-\mathrm{T}} \mathbf{C}_{T} \mathbf{J}^{-1}\left[\begin{array}{l}
\dot{\mathbf{u}}_{T} \\
\dot{\boldsymbol{\theta}}_{T}
\end{array}\right]+} \\
+\mathbf{J}^{-\mathrm{T}} \mathbf{K}_{T} \mathbf{J}^{-1}\left[\begin{array}{c}
\mathbf{u}_{T} \\
\boldsymbol{\theta}_{T}
\end{array}\right]=-\left[\begin{array}{c}
\mathbf{R} \mathbf{F}_{\text {mac }} \\
\mathbf{R}\left(\mathbf{M}_{\text {mac }}+\mathbf{r} \times \mathbf{F}_{\text {mac }}\right)
\end{array}\right] .
\end{gathered}
$$

where $\mathbf{I}_{3}$ is the $3 \times 3$ identity matrix; $\mathbf{K}_{T}$ is a $6 \times 6$ diametric matrix whose elements are the equivalent stiffness coefficient, $K_{T i} ; \mathbf{C}_{T}$ is also a $6 \times 6$ diametric matrix whose elements are the equivalent damping coefficient, $C_{T i}$.

The coupled vibration equation of the platform can be expressed in compact form as:

$$
\begin{gathered}
\mathbf{M}_{\mathrm{V}}\left[\begin{array}{c}
\ddot{\mathbf{u}}_{T} \\
\ddot{\boldsymbol{\theta}}_{T}
\end{array}\right]+\mathbf{C}_{\mathrm{V}}\left[\begin{array}{c}
\dot{\mathbf{u}}_{T} \\
\dot{\boldsymbol{\theta}}_{T}
\end{array}\right]+\mathbf{K}_{\mathrm{V}}\left[\begin{array}{l}
\mathbf{u}_{T} \\
\boldsymbol{\theta}_{T}
\end{array}\right]=\mathbf{F}_{\mathrm{V}} . \\
\text { 4 FORCED VIBRATION OF THE TABLE } \\
\text { USING AN ANALYTICAL APPROACH AND FEM }
\end{gathered}
$$

To investigate the forced vibration of the table, the external force on the platform has been assumed to be a sinusoid force [12]; thus, Eq. (11) can be rephrased as follows:

$$
\mathbf{M}_{\mathrm{V}}\left[\begin{array}{c}
\ddot{\mathbf{u}}_{T} \\
\ddot{\boldsymbol{\theta}}_{T}
\end{array}\right]+\mathbf{C}_{\mathrm{V}}\left[\begin{array}{c}
\dot{\mathbf{u}}_{T} \\
\dot{\boldsymbol{\theta}}_{T}
\end{array}\right]+\mathbf{K}_{\mathrm{V}}\left[\begin{array}{c}
\mathbf{u}_{T} \\
\theta_{T}
\end{array}\right]=\mathbf{F}_{\mathrm{V}} \sin (\omega t)
$$

where $\omega$ is the frequency related to the sinusoid force and moment.

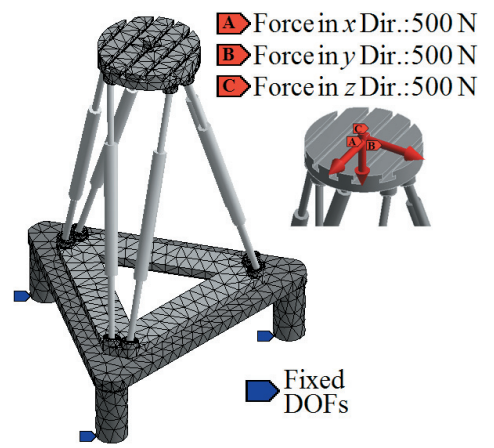

Fig. 7. The discretized model of the manipulator

The vibration of the moving platform can, ultimately, be analysed using the above equation when its matrix coefficients are specified. The resonance frequencies and vibrations of the platform in the linear and rotational directions (i.e. $\mathbf{u}_{T}$ and $\boldsymbol{\theta}_{T}$ ) are obtained using a programme written in MATLAB. The programme developed in the present work uses the MATLAB routine ODE45, which is based on the $4^{\text {th }}$ and $5^{\text {th }}$ order Runge-Kutta formulas with adaptive step-size, for solving the system of differential equations. In order to verify the results, the resonance frequencies and the vibrations of the platform are also obtained using the Full Solution Method in FEM harmonic analysis. For this purpose, a three-dimensional model of the hexapod table was developed in Solidworks. The pods are neglected in the CAD model.

The model is exported to the ANSYS Workbench and the equivalent damping and stiffness of the pods (i.e. $C_{T i}$ and $K_{T i}$ ) are applied instead of the pods; the necessary input data as material properties are also applied, afterwards elements of the model executed using Solid element. The model has 12589 elements and 23208 nodes. In the case of a model with a maximum payload, a cubic part with a maximum mass is modelled on the moving platform; this model has 12884 elements and 23770 nodes.

Afterwards, the relevant boundary conditions are applied to the foundation connection of the manipulator and harmonic analysis was then carried out to obtain the harmonic response of the platform. The discretized model in the ANSYS Workbench with the relevant boundary conditions and external forces acting on the moving platform are shown in Fig. 7. 

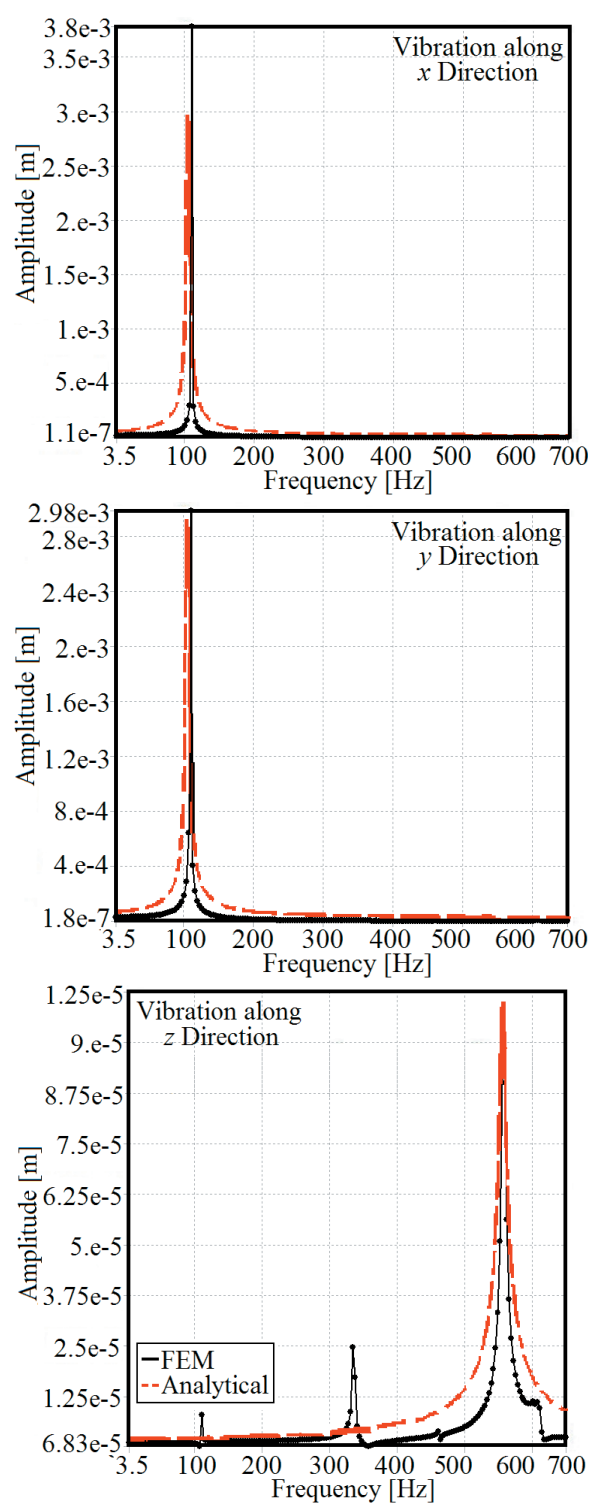

Fig. 8. Vibrations of the moving platform obtained using an analytical approach and FEM

The forced vibration of the platform has been examined using an analytical approach and FEM for a configuration of the mechanism where pods are completely open and the moving platform is in its upmost position, disoriented and without payload. In this simulation the amplitudes of the external moment have been assumed to be zero and the external force have been presumed to be $\mathbf{F}_{e x t}=[500 \mathrm{~N} 500 \mathrm{~N} 500 \mathrm{~N}]^{\mathrm{T}}$ and for the simulation.

As a result of the analytical and FEM simulation, the ratio of the response amplitude to the base excitation amplitude against the base excitation frequency are shown in Fig. 8 as the amplitude of the displacements and rotations of the moving platform in the frequency domain and in $x, y$ and $z$ directions. There are some lower peaks in the diagrams, and these peaks are generally due to some important resonance frequencies in other directions. For instance, the first lower peak in the figure for vibrations in the z-direction is at $112 \mathrm{~Hz}$ which directly shows the effect of vibrations in the $x$ direction. The vibrations in the $x$ direction (3.8e-3) are considerably higher than vibrations in the $z$ direction (1.25e-5). Therefore, these vibrations may be visible in harmonic analysis of vibrations in the $z$ direction.

Table 2. Different configurations of the moving platform

\begin{tabular}{cccc}
\hline $\begin{array}{c}\text { Configuration } \\
\text { number }\end{array}$ & $\begin{array}{c}\text { Centre position } \\
\text { of the moving } \\
\text { platform }\end{array}$ & $\begin{array}{c}\text { Centre position } \\
\text { of the moving } \\
\text { platform X, Y, Z } \\
{[\mathrm{mm}]}\end{array}$ & $\begin{array}{c}\text { Mass of the } \\
\text { platform and the } \\
\text { payload } \\
{[\mathrm{kg}]}\end{array}$ \\
\hline 1 & $\begin{array}{c}\text { Bottommost } \\
\text { Position }\end{array}$ & $0,0,710$ & 40.6 \\
\cline { 3 - 4 } & Middle & $0,0,710$ & 90.6 \\
\cline { 3 - 4 } & position & $0,0,820$ & 40.6 \\
\hline 3 & Upmost & $0,0,820$ & 90.6 \\
\hline 5 & position & $0,0,930$ & 40.6 \\
\hline 6 & & & 90.6 \\
\hline
\end{tabular}

In general, the reason for the extra lower peaks predicted by FEM may attributed to the FEM harmonic analysis in the ANSYS Workbench program. In this analysis all the vibrational properties of the system are taken into account and a complete vibration model of the system is used to obtain resonance frequencies and displacements, whereas in the analytical model written in MATLAB, a reduced model is applied.

$C_{T i}$ and $K_{T i}$, are greatly influenced by the variation in the position and orientation of the moving platform. Total mass and inertia of the moving platform, $\mathrm{mp}$ and Ip, could also be affected by the impact of the variation in the weight and shape, respectively, of the dead weight installed on it.

Depending on the configuration of the platform, natural and resonance frequencies will vary significantly. Therefore, six different configurations have been selected in the vicinity of the workspace to specify variations in the resonance frequencies of the moving platform (see Table 2).

The results of the analytical approach and FEM for the resonance frequencies of the moving platform in different configurations are reported in Table 3. In Table 3, six resonance frequencies are presented for six linear and rotational directions. According to this table, the results of both methods are highly consistent. This can be better visualized from the comparative diagrams in Fig. 9. 
Table 3. Resonance frequencies of the platform (in $\mathrm{Hz}$ ) obtained using an analytical approach and FEM

\begin{tabular}{lccccccc}
\hline Configurations & (Table 1) & 1 & 2 & 3 & 4 & 5 & 6 \\
\hline Frequency & Analytical & 218 & 146 & 147 & 98 & 111 & 75 \\
\cline { 2 - 8 } along $x$ axis & FEM & 211 & 156 & 147 & 104 & 112 & 81 \\
\hline Frequency & Analytical & 218 & 146 & 147 & 98 & 111 & 75 \\
\cline { 2 - 8 } along $y$ axis & FEM & 213 & 157 & 148 & 105 & 113 & 81 \\
\hline Frequency & Analytical & 356 & 314 & 239 & 211 & 181 & 160 \\
\cline { 2 - 7 } along $z$ axis & FEM & 358 & 303 & 246 & 200 & 187 & 152 \\
\hline Frequency & Analytical & 838 & 557 & 665 & 431 & 570 & 369 \\
\cline { 2 - 7 } around $x$ axis & FEM & 729 & 523 & 619 & 426 & 557 & 374 \\
\hline Frequency & Analytical & 859 & 573 & 699 & 444 & 599 & 380 \\
\cline { 2 - 7 } around $y$ axis & FEM & 732 & 528 & 621 & 428 & 597 & 377 \\
\hline Frequency & Analytical & 912 & 604 & 707 & 469 & 605 & 403 \\
\cline { 2 - 7 } around $z$ axis & FEM & 856 & 546 & 634 & 456 & 602 & 385 \\
\hline
\end{tabular}

The least resonance frequencies occur in the configuration in which the moving platform with the most payloads is in the upmost border of the workspace (configuration six of Table 2). This is the configuration where the length of the pods is at a maximum, i.e. they have the lowest stiffness coefficients.

With a decrease in the equivalent stiffness of the pods and an increase in the mass, the natural frequencies of the table will be diminished. On the other hand, upon reduction in the length of the pods in the lower position of the moving platform, their equivalent stiffness will be increased. This phenomenon and the decrease in the mass of the payload on the platform are two factors leading to an increase in natural frequencies. Thus, it is obvious that the factors influencing natural frequencies will also significantly influence the resonance frequencies of the moving platform. It is accepted that changes in the payload on the platform and the position (especially in direction $z$ ) will induce more changes in total mass and stiffness matrices in the vibration equation of the platform, and consequently the natural frequencies and the resonance frequencies of the moving platform will be affected.

The results of both the analytical approach and FEM are obtained for the range of the maximum vibrations in different directions and in each of the configurations of Table 2 and are presented in Table 4 .

Another observation is that changes in the magnitude of the external force and moment do not cause any change in the resonance frequencies of the moving platform. It is obvious that these changes are directly related to the change in the amplitude of the vibrations.
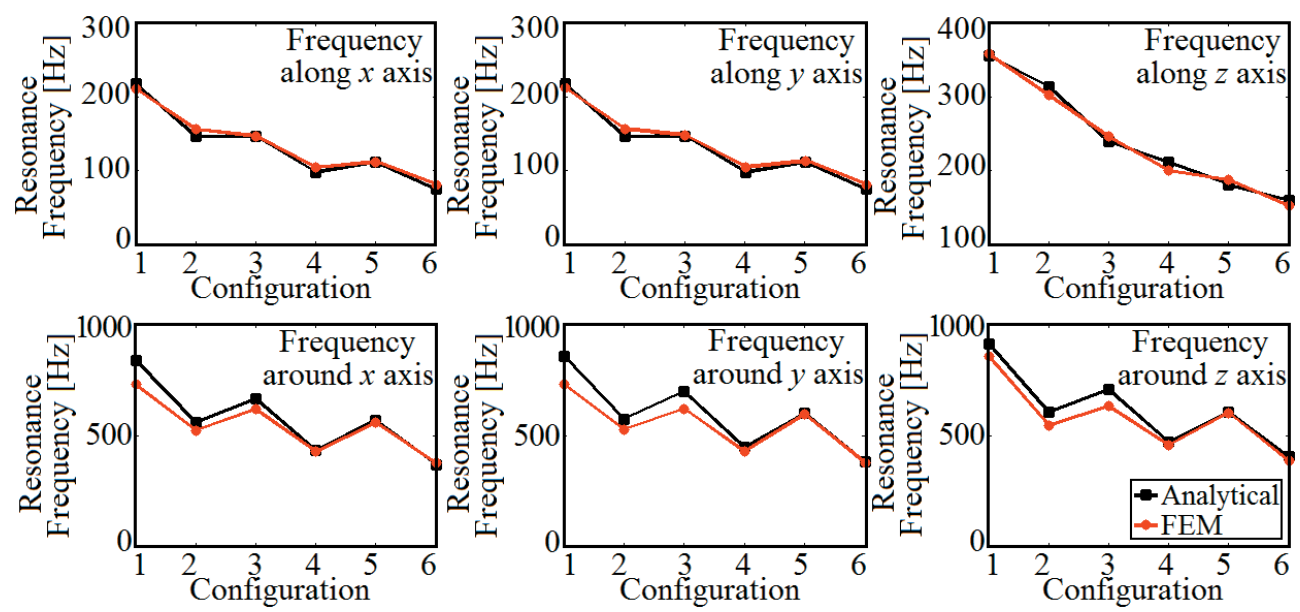

Fig. 9. Comparison between the results of the analytical approach and FEM for vibrations of the platform

Table 4. Range of maximum vibrations of the platform (in $\mathrm{mm}$ ) for different configurations of the table obtained using the analytical approach and FEM

\begin{tabular}{ccccccc}
\hline & Max vibration & Max vibration & Max vibration \\
along X & along Y & along Z & $\begin{array}{c}\text { Max vibration } \\
\text { along } X\end{array}$ & $\begin{array}{c}\text { Max vibration } \\
\text { along Y }\end{array}$ & \multirow{2}{*}{ Max vibration along Z } \\
\hline \multirow{2}{*}{ Analytical } & $\begin{array}{c}8.57 \mathrm{e}-4 \\
\text { to } 2.94 \mathrm{e}-3\end{array}$ & $\begin{array}{c}8.67 \mathrm{e}-4 \\
\text { to } 2.97 \mathrm{e}-3\end{array}$ & $\begin{array}{c}3.18 \mathrm{e}-5 \\
\text { to } 1.62 \mathrm{e}-4\end{array}$ & $\begin{array}{c}8.10 \mathrm{e}-5 \\
\text { to } 2.93 \mathrm{e}-4\end{array}$ & $\begin{array}{c}6.24 \mathrm{e}-6 \text { to } \\
1.91 \mathrm{e}-5\end{array}$ & \multirow{2}{*}{$1.64 \mathrm{e}-5$ to $2.97 \mathrm{e}-4$} \\
\hline \multirow{2}{*}{ FEM } & $7.80 \mathrm{e}-4$ & $7.53 \mathrm{e}-4$ & $\begin{array}{c}3.86 \mathrm{e}-5 \\
\text { to } 2.15 \mathrm{e}-4\end{array}$ & $\begin{array}{c}7.63 \mathrm{e}-5 \\
\text { to } 3.93 \mathrm{e}-4\end{array}$ & $\begin{array}{c}5.34 \mathrm{e}-6 \text { to } \\
2.02 \mathrm{e}-5\end{array}$ & $2.06 \mathrm{e}-5$ to $3.64 \mathrm{e}-4$ \\
\hline
\end{tabular}




\section{FORCED VIBRATION OF THE TABLE UNDER MACHINING FORCES}

Forced vibrations have a strong impact on the machining process when one or more of the frequencies of the cyclic shock and varying cutting force are equal or close to one or more of the natural frequencies of the machining system [13].

To this end, it seems vital to devise a comprehensive model with the capability of exactly predicting the machining process, depending on the exact modelling process of the machining forces. Thus, in order to closely examine the forced vibration as a result of the machining process on the hexapod table under study, milling forces have been modelled taking into account the range of changes in forces and different milling operations (up and down).

In essence, determining the forced vibration of the platform and examining its forced response under harmonic milling forces plays a crucial role in eliminating resonance.

The relationship between the direction of tool rotation and feed defines the two types of milling operations: up milling and down milling [14] and [15]. Considering the end milling process model (Fig. 10), the magnitude of forces and moments during milling are comparable. In this study, forces and moments during milling have been modelled using force equations presented in [16] using a code written in MATLAB.

As mentioned in reference [16], tangential $F_{t}(\varphi)$, radial $F_{r}(\varphi)$ and axial $F_{a}(\varphi)$ components of cutting forces can be expressed as a function of varying uncut chip area $a h(\varphi)$; yielding:

$$
\begin{aligned}
& F_{t}(\varphi)=K_{t} a h(\varphi), \\
& F_{r}(\varphi)=K_{r} a h(\varphi), \\
& F_{a}(\varphi)=K_{a} a h(\varphi),
\end{aligned}
$$

where $K_{t}, K_{r}$ and $K_{a}$ are the cutting force coefficients contributed by the shearing action in the tangential, radial and axial directions, respectively; $\varphi$ is the instantaneous angle of immersion. $a$ is the edge contact length (axial depth of cut) and $h(\varphi)$ is the time dependent chip thickness variation.

Chip thickness can be expressed as:

$$
h(\varphi)=f_{z} \sin (\varphi),
$$

in which $f_{z}$ is the feed per tooth [mm/rev-tooth].

Considering Fig. 10, horizontal $F_{x}(\varphi)$, normal $F_{y}(\varphi)$ and axial $F_{z}(\varphi)$ components of cutting forces can be derived as:

$$
\begin{gathered}
F_{x}(\varphi)=-F_{t}(\varphi) \cos (\varphi)-F_{r}(\varphi) \sin (\varphi), \\
F_{y}(\varphi)=-F_{t}(\varphi) \sin (\varphi)-F_{r}(\varphi) \cos (\varphi), \\
F_{z}(\varphi)=F_{a}(\varphi),
\end{gathered}
$$

The instantaneous cutting torque, $T_{c}(\varphi)$, can be obtained as:

$$
T_{c}(\varphi)=F_{t}(\varphi) D / 2,
$$

where $D$ is the diameter of the milling cutter.
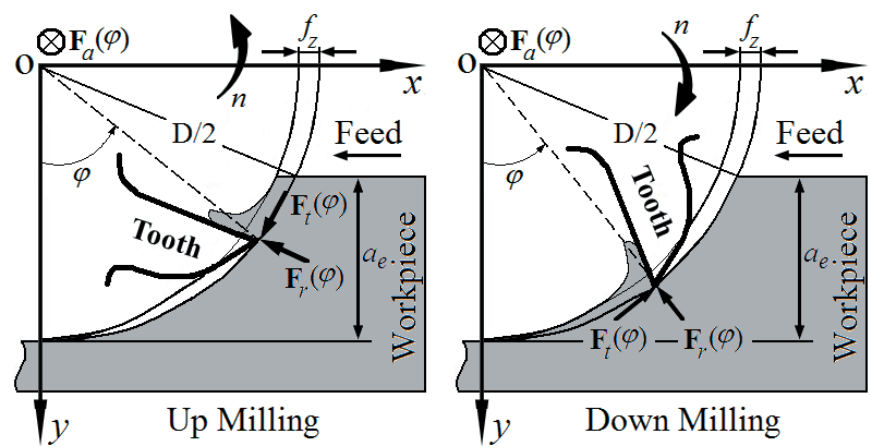

Fig. 10. Geometry of the milling process with cutting force components on the tooth

Table 5. Range of the resonance frequencies of the platform (in $\mathrm{Hz}$ ) for different configurations of the manipulator and different cutting conditions

\begin{tabular}{ccccccc}
\hline & $\begin{array}{c}\text { Resonance freq. } \\
\text { along } x\end{array}$ & $\begin{array}{c}\text { Resonance freq. } \\
\text { along } y\end{array}$ & $\begin{array}{c}\text { Resonance freq. } \\
\text { along } z\end{array}$ & $\begin{array}{c}\text { Resonance freq. } \\
\text { around } x\end{array}$ & $\begin{array}{c}\text { Resonance freq. } \\
\text { around } y\end{array}$ & $\begin{array}{c}\text { Resonance freq. } \\
\text { around } z\end{array}$ \\
\hline Min & 74 & 72 & 388 & 380 & 358 & 156 \\
\hline Max & 178 & 175 & 748 & 712 & 665 & 278 \\
\hline
\end{tabular}


Considering the spindle speed, $n$ [rpm], and the number of teeth on cutter, $Z$, tooth passing frequency, $f$ $[\mathrm{Hz}]$, can be obtained as:

$$
f=n Z / 60 .
$$

In this study, milling forces and moments have been presumed to be the external forces and moments acting on the moving platform; therefore, the external force and moment vectors can be defined as $\mathbf{F}_{m a c}=\left[\begin{array}{lll}F_{x}(\varphi) & F_{y}(\varphi) & F_{z}(\varphi)\end{array}\right]^{\mathrm{T}}$ and $\mathbf{M}_{m a c}=\left[\begin{array}{lll}0 & 0 & T_{c}(\varphi)\end{array}\right]^{\mathrm{T}}$, respectively.

In this way, forced vibrations of the platform as the result of milling forces can be examined, since the mass, damping, stiffness and force matrices in Eq. (11) are known.

\section{CASE STUDY}

Assuming the following parameters for each condition of roughing and finishing of the workpiece (material: Ti6Al4V) with an end mill cutter with three flutes and $20 \mathrm{~mm}$ diameter:

roughing: $a_{e}=20 \mathrm{~mm}, a=4 \mathrm{~mm}, f_{z}=0.15 \mathrm{~mm}$, finishing: $a_{e}=20 \mathrm{~mm}, a=1 \mathrm{~mm}, f_{z}=0.10 \mathrm{~mm}$, where $a_{e}$ is the radial depth of cut.

Considering the spindle speed as 200 to 20000 rpm, tooth passing frequency is calculated using Eq. (21) and vibrations of the moving platform in the frequency domain of 10 to $1000 \mathrm{~Hz}$, corresponding to the cutting speed of the spindle in all conditions of roughing and finishing for both up and down milling operations and for the configurations mentioned in Table 2 have been analysed.

The findings of the analytical approach are given in Table 5 for the range of the resonance frequencies of the platform for different configurations of the manipulator and different cutting conditions.

The range of the maximum vibration amplitudes of the moving platform as a result of the milling forces has been examined, considering the different milling operations and the different configurations of the platform mentioned in Table 2. Table 6 lists the results of the simulation.
In the present investigation, the lowest vibrations in all directions occur in the configuration in which the centre of the moving platform is located in the bottommost position of the workspace and up milling forces are applied in finishing. On the other hand, with the centre of the platform in the upper position and during roughing, more vibrations will occur.

For example, the amplitude of vibrations and the resonance frequencies of these forces for the upmost position of the disoriented moving platform have been investigated against the base excitation frequency and for the minimum and maximum payload on it. The results of the simulation are illustrated in Figs. 11 and 12 for different cutting conditions. Fig. 11 illustrates the amplitude of the vibrations and resonance frequencies for the upmost position of the disoriented moving platform under up milling and for two different machining strategies of roughing and finishing. Fig. 12 also presents the results obtained by analytical simulation as the amplitude of vibrations and resonance frequencies for the upmost position of the disoriented moving platform under down milling and for two different machining conditions of roughing and finishing.

Considering the results of the displacements of the moving platform as the result of different milling forces, one can infer that the range of displacement of the moving platform is proportionate to the applied force on it. Therefore, all effective parameters changing the cutting forces including cutting and geometrical parameters will influence the amplitudes of the vibrations of the moving platform. For instance, increasing the feed rate, depth of cut and number of teeth of the cutter causes an increase in cutting force parameters [17] and [18]. Thus, an increase in these factors leads to enhancement of vibrations of the platform under machining forces. It is also to be noted that increasing the spindle speed will decrease the coefficients of the cutting forces and therefore the cutting force and amplitudes of the vibrations of the platform will be decreased.

Table 6. Range of vibrations of the platform ( $\mathrm{m}$ for displacements and rad for rotations) for different configurations of manipulator and different cutting conditions

\begin{tabular}{cccccccc}
\hline & & Vibration along $x$ & Vibration along $y$ & Vibration along $z$ & Vibration around $x$ & Vibration around $y$ & Vibration around $z$ \\
\hline \multirow{2}{*}{$\begin{array}{c}\text { Up } \\
\text { milling }\end{array}$} & Roughing & $9.96 \mathrm{e}-5$ to $4.53 \mathrm{e}-4$ & $1.21 \mathrm{e}-4$ to $5.93 \mathrm{e}-4$ & $9.55 \mathrm{e}-6$ to $3.71 \mathrm{e}-5$ & $9.30 \mathrm{e}-5$ to $2.93 \mathrm{e}-4$ & $5.27 \mathrm{e}-6$ to $2.01 \mathrm{e}-5$ & $1.64 \mathrm{e}-4$ to $2.97 \mathrm{e}-3$ \\
\cline { 2 - 8 } & Finishing & $1.76 \mathrm{e}-5$ to $8.03 \mathrm{e}-5$ & $2.48 \mathrm{e}-5$ to $1.34 \mathrm{e}-4$ & $9.35 \mathrm{e}-7$ to $6.87 \mathrm{e}-6$ & $1.55 \mathrm{e}-5$ to $4.47 \mathrm{e}-5$ & $1.20 \mathrm{e}-6$ to $3.17 \mathrm{e}-6$ & $3.12 \mathrm{e}-5$ t0 $6.71 \mathrm{e}-4$ \\
\hline \multirow{2}{*}{$\begin{array}{c}\text { Down } \\
\text { milling }\end{array}$} & Roughing & $1.99 \mathrm{e}-5$ to $1.37 \mathrm{e}-4$ & $1.84 \mathrm{e}-4$ to $9.01 \mathrm{e}-4$ & $5.40 \mathrm{e}-6$ to $3.48 \mathrm{e}-5$ & $1.26 \mathrm{e}-4$ to $3.93 \mathrm{e}-4$ & $3.95 \mathrm{e}-5$ to $1.38 \mathrm{e}-4$ & $1.82 \mathrm{e}-4$ to $3.14 \mathrm{e}-4$ \\
\cline { 2 - 8 } & Finishing & $4.04 \mathrm{e}-6$ to $2.71 \mathrm{e}-5$ & $3.03 \mathrm{e}-5$ to $1.49 \mathrm{e}-4$ & $9.51 \mathrm{e}-7$ to $6.25 \mathrm{e}-5$ & $2.13 \mathrm{e}-5$ to $6.48 \mathrm{e}-5$ & $6.76 \mathrm{e}-6$ to 2.11e-5 & $3.24 \mathrm{e}-5$ to $6.59 \mathrm{e}-4$ \\
\hline
\end{tabular}



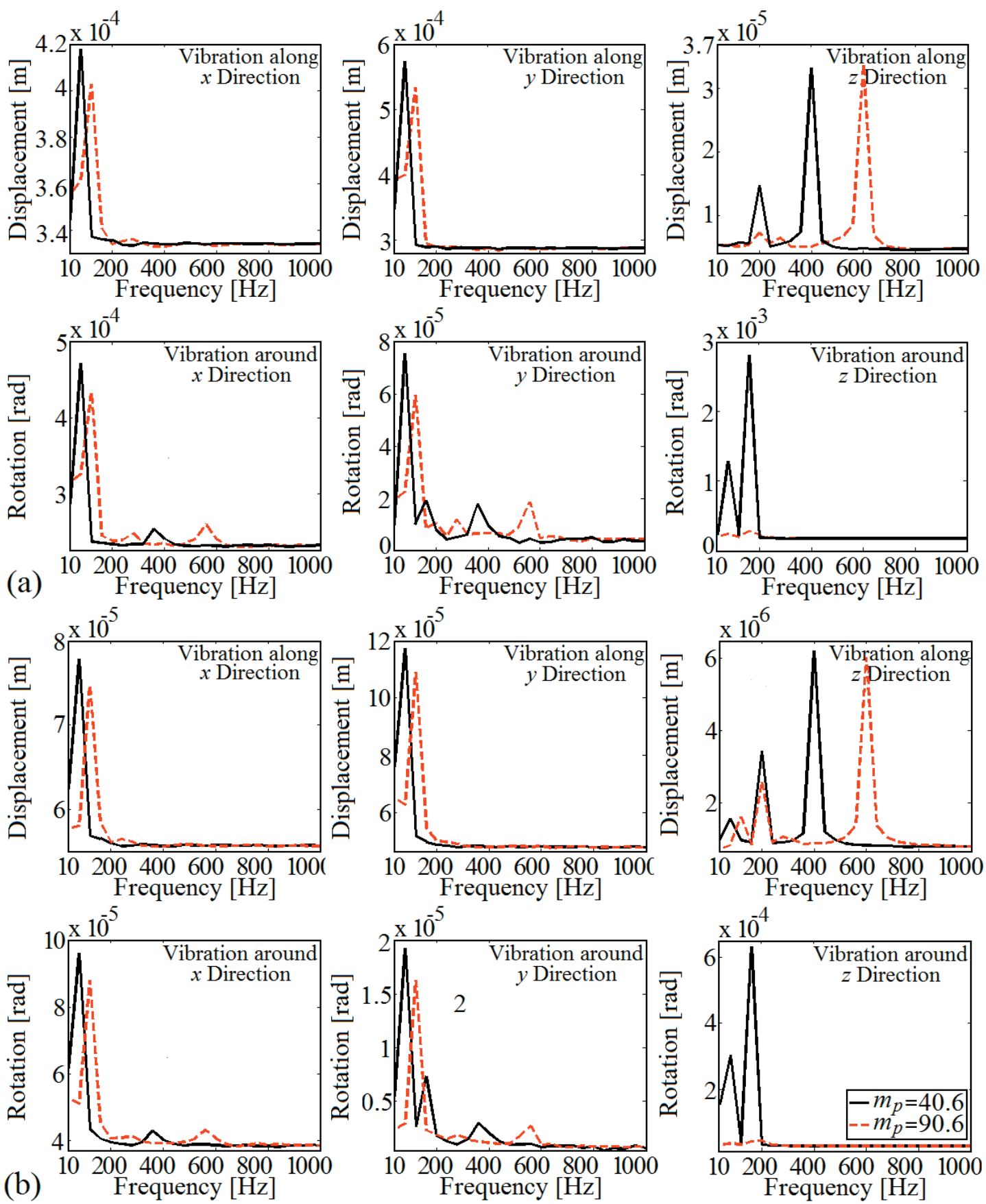

Fig. 11. Vibrations of the moving platform in different directions and in different up milling operation: a) roughing, b) finishing

\section{CONCLUSION AND DISCUSSIONS}

In the present study, forced vibrations of the hexapod table were examined using two methods, analytical and finite elements. Considering a sample sinusoid force acting on the platform, the resonance frequencies and the range of vibrations of the platform were calculated based on a programme written in MATLAB. In order to verify the results of the analytical approach, harmonic analysis of the table was carried out in ANSYS Workbench under the same conditions. It was found that the results of both methods exhibit a satisfactory level of consistency. In this study, examination of the results of the analytical approach and FEM indicated that the mechanism of the case study can be calculated in terms of the characteristics 

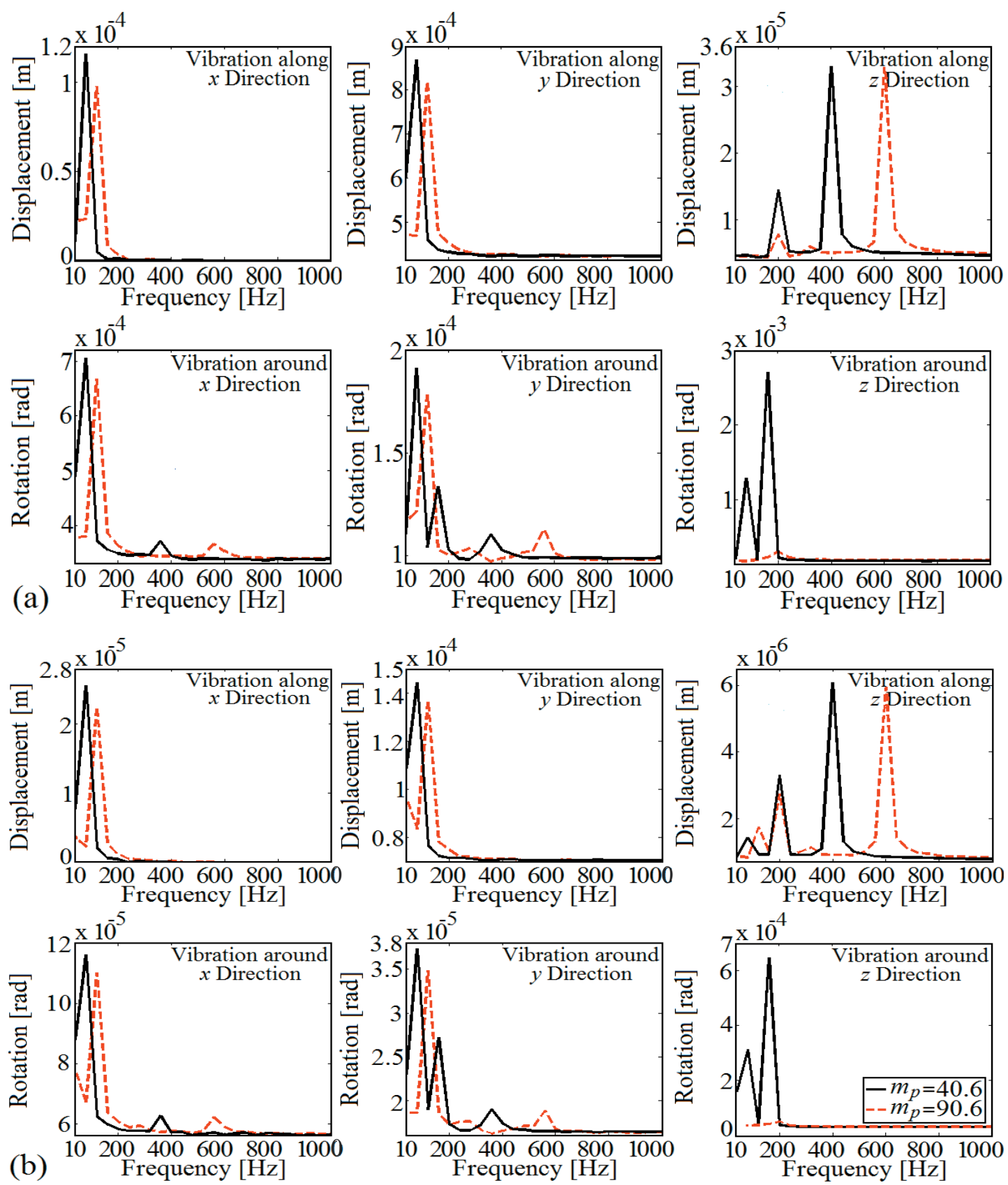

Fig. 12. Vibrations of the moving platform in different directions and in different down milling operations: a) roughing, b) finishing

of the external forces. Therefore, the resonance frequencies and the vibrations of the moving platform can be obtained for any periodic external force when the mass, damping and stiffness matrices are available. Forced vibrations of the moving platform were examined in different configurations and at different resonance frequencies and the range of platform vibrations for different machining operations were calculated in the present study. Determination of the resonance frequencies and the range of the vibrations of the platform as a result of the machining forces is the best method for defining conditions conducive to resonance. Thus, with a careful choice of machining parameters, conditions conducive to chatter in the milling process can be avoided.

According to the investigations, the lowest resonance frequencies occur in a configuration in which the moving platform is in the upmost position with the maximum payload on it. On the other hand, maximum vibrations of the moving platform are found 
for the same configuration when up milling forces are applied during the roughing process. Therefore, in order to avoid dynamic instability during the machining process in upper positions, higher cutting speed and lower cutting force are recommended and hence, upper positions of the platform will be the most proper position for high speed machining. Finishing is carried out at high cutting speeds with a lower feed rate and depth of cut. Thus, machining forces exerted on the platform will have a small magnitude under finishing conditions. It can be concluded that upper positions of the platform are the best positions for the finishing process. To produce an appropriate surface finish in upper positions of the moving platform, down milling would be the best option.

Shortening the length of the pods in lower positions of the moving platform together with decreasing the payload mass are two factors contributing to the increase in the resonance frequencies of the hexapod table. Therefore, the lower positions of the platform will help the mechanism withstand high machining forces. In lower positions of the platform, the vibrations as the result of these forces would be at a minimum. Therefore, in the lower positions of the platform, machining at lower cutting speeds would be possible and these positions would be appropriate for roughing. Furthermore, in order to decrease shocks by roughing in the lower positions, up milling would be the most appropriate method.

\section{APPENDIX 1}

The physical specifications of the test manipulator are as follows:

$\begin{array}{ll}\text { Radius of the moving platform } & 175 \mathrm{~mm} ; \\ \text { Radius of the base } & 400 \mathrm{~mm} ; \\ \text { Angular distance between } & \\ \text { two adjacent spherical joints } & 30^{\circ} ; \\ \text { Angular distance between } & \\ \text { two adjacent universal joints } & 14^{\circ} ; \\ \text { Minimum length of each pod } & 760.2 \mathrm{~mm} ; \\ \text { Maximum length of each pod } & 968.9 \mathrm{~mm} ; \\ \text { Minimum mass of moving } & \\ \text { platform together with payload } & 40.6 \mathrm{~kg} ; \\ \text { Maximum mass of moving } & \\ \text { platform together with payload } & 90.6 \mathrm{~kg} ; \\ \text { Maximum course in } & x \text { axis }= \pm 130 \mathrm{~mm}, \\ \text { in } & y \text { axis }= \pm 130 \mathrm{~mm}, \\ \text { and in } & z \text { axis }=220 \mathrm{~mm} .\end{array}$

\section{APPENDIX 2}

Considering ${ }^{\mathrm{P}} \mathbf{I}_{p}$ as the inertia tensor of the moving platform and the payload in frame $\{\mathbf{P}\}$, the inertia tensor of the moving platform and the payload in base frame, $\mathbf{I}_{p}$, can be obtained using the parallel axes theorem [19] and [20], which yields:

$$
\mathbf{I}_{p}=\mathbf{R}\left({ }^{\mathrm{P}} \mathbf{I}_{p}+m_{p}\left[\begin{array}{ccc}
r_{y}^{2}+r_{z}^{2} & -r_{x} r_{y} & -r_{x} r_{z} \\
-r_{x} r_{y} & r_{x}^{2}+r_{z}^{2} & -r_{y} r_{z} \\
-r_{x} r_{z} & -r_{y} r_{z} & r_{x}^{2}+r_{y}^{2}
\end{array}\right]\right) \mathbf{R}^{\mathrm{T}},
$$

where $\mathbf{R}$ is the rotation $3 \times 3$ matrix, representing the rotation of the frame $\{\mathbf{P}\}$ related to frame $\{\mathbf{W}\}$, and can be obtained by:

$$
\mathbf{R}=\left[\begin{array}{ccc}
C \theta_{z} C \theta_{y} & -S \theta_{z} C \theta_{x}+C \theta_{z} S \theta_{y} S \theta_{x} & S \theta_{z} S \theta_{x}+C \theta_{z} S \theta_{y} C \theta_{x} \\
S \theta_{z} C \theta_{y} & C \theta_{z} C \theta_{x}+S \theta_{z} S \theta_{y} S \theta_{x} & -C \theta_{z} S \theta_{x}+S \theta_{z} S \theta_{y} C \theta_{x} \\
-S \theta_{y} & C \theta_{y} S \theta_{x} & C \theta_{y} C \theta_{x}
\end{array}\right],
$$

in which $C \theta_{x}=\cos \left(\theta_{x}\right)$ and $S \theta_{x}=\sin \left(\theta_{x}\right)$ and the vector $\mathbf{r}=\left[\begin{array}{lll}r_{x} & r_{y} & r_{z}\end{array}\right]^{\mathrm{T}}$ is the position vector of the mass centre of the moving platform and the payload in frame $\{\mathbf{W}\}$ and can be obtained by:

$$
\mathbf{r}=\mathbf{R r}_{o}
$$

in which $\mathbf{r}_{o}$ is the position vector of the mass centre of the moving platform and the payload in frame $\{\mathbf{P}\}$. The inverse Jacobian matrix can be expressed as:

$$
\mathbf{J}^{-1}=\left[\begin{array}{cc}
\mathbf{n}_{1}^{\mathrm{T}} & \left(\mathbf{q}_{1} \times \mathbf{n}_{1}\right)^{\mathrm{T}} \\
\vdots & \vdots \\
\mathbf{n}_{6}^{\mathrm{T}} & \left(\mathbf{q}_{6} \times \mathbf{n}_{6}\right)^{\mathrm{T}}
\end{array}\right] .
$$

\section{REFERENCES}

[1] Dohner, J.L., Kwan, C.M., Regerlbrugge, M.E. (1996). Active Chatter Suppression in an Octahedral Hexapod Milling Machine: A Design Study. Proceedings of SPIE-The International Society for Optical Engineering, vol. 2721, p. 316-325.

[2] Hardage, D.S., Wiens, G.J (1999). Modal analysis and modeling of a parallel kinematic machine. Journal of Manufacturing Science and Engineering, vol. 10, p. 857-862.

[3] Hardage, D.S. (2000). Structural dynamics of parallel kinematic machines. $\mathrm{PhD}$ Thesis, University of Florida, Gainesville.

[4] Wiens, G.J., Hardage, D.S. (2006). Structural dynamics and system identification of parallel kinematic machines. Proceedings of IDETC/CIE, vol. 99671.

[5] Ting, Y., Chen, Y-S., Jar, H-C. (2004). Modeling and control for a Gough-Stewart platform CNC machine. 
Journal of Robotic Systems, vol. 21, p. 609-623, DOI:10.1002/rob.20039.

[6] Mukherjee, P., Dasgupta, B., Mallik, A.K. (2007). Dynamic stability index and vibration analysis of a flexible Stewart platform. Journal of Sound and Vibration, vol. 307, no. 3-5, p. 495-512, DOI:10.1016/j. jsv.2007.05.036.

[7] Hong. D., Kim. S., Choi. W.C., Song. J-B. (2003). Analysis of machining stability for a parallel machine tool. Mechanics Based Design of Structures and Machines, vol. 31, p. 509-528, DOI:10.1081/SME120023169 .

[8] Mahboubkhah, M., Nategh, M.J., Esmaeilzadeh Khadem, S. (2008). Vibration analysis of machine tools' hexapod table. The International Journal of Advanced Manufacturing Technology, vol. 38, p. 12361243, DOI:10.1007/s00170-007-1183-9.

[9] Mahboubkhah, M., Nategh, M.J., Esmaeilzadeh Khadem, S. (2009). A Comprehensive Study on the Free Vibration of Machine Tools' Hexapod Table. The International Journal of Advanced Manufacturing Technology, vol. 40, p. 1239-1251, DOI:10.1007/ s00170-008-1433-5.

[10] Pedrammehr, S., Mahboubkhah, M., Khani, N. (2013). A study on vibration of Stewart platformbased machine tool table. The International Journal of Advanced Manufacturing Technology, vol. 65, p. 9911007, DOI:10.1007/s00170-012-4234-9.

[11] Maia, N.M., Silva, J.M.E. (1997) Theoretical and Experimental Modal Analysis. Research Studies Press, New Delhi.

[12] Tobias, S.A. (1965). Machine-Tool Vibration. Blackie and Sons Ltd., London.
[13] Cheng, K. (2009). Machining Dynamics, Fundamentals, Applications and Practices. SpringerVerlag, London.

[14] Insperger, T., Mann, B.P., Stépán, G., Bayly, P.V. (2003). Stability of up-milling and down-milling, part 1: alternative analytical methods. International Journal of Machine Tools and Manufacture, vol. 43, p. 25-34, DOI:10.1016/S0890-6955(02)00159-1.

[15] Long, X-H., Balachandran, B. (2007). Stability analysis for milling process. Nonlinear Dynamics, vol. 49, p. 349-359, DOI:10.1007/s11071-006-9127-8.

[16] Altintas, Y. (2000). Manufacturing Automation, Metal Cutting Mechanics, Machine Tool Vibrations and CNC Design. Cambridge University Press, UK.

[17] Mann, B.P., Insperger, T., Bayly, P.V., Stépán, G. (2003). Stability of up-milling and down-milling, part 2: experimental verification. International Journal of Machine Tools and Manufacture, vol. 43, p. 35-40, DOI:10.1016/S0890-6955(02)00160-8.

[18] Yangui, H., Zghal, B., Kessentini, A., Chevallier, G., Riviere, A., Haddar, M., Karral, C. (2010). Influence of Cutting and Geometrical Parameters on the Cutting Force in Milling. Scientific Research, Engineering, vol. 2, p. 751-761, DOI:10.4236/eng.2010.210097.

[19] Pedrammehr, S., Mahboubkhah, M., Pakzad, S. (2011). An improved solution to the inverse dynamics of the general Stewart platform. Proceedings of IEEE International Conference on Mechatronics, no. 5971317, p. 392-397.

[20] Pedrammehr, S., Mahboubkhah, M., Khani, N. (2012). Improved Dynamic Equations for the Generally Configured Stewart Platform Manipulator. Journal of Mechanical Science and Technology, vol. 26, p. 711721, DOI:10.1007/s12206-011-1231-0. 